\title{
Adenocarcinoma de pulmón con patrón de crecimiento lepídico
}

Daniel Etxeberria-Lekuona, Amaia Atenea Iridoy-Zulet

Servicio de Medicina Interna. Hospital García Orcoyen. Estella. Navarra. España

Recibido: 11/07/2020

Aceptado: 22/10/2020

En línea: 31/12/2020

Citar como: Etxeberria-Lekuona D, Iridoy-Zulet AA. Adenocarcinoma de pulmón con patrón de crecimiento lepídico. Rev Esp Casos Clin Med Intern (RECCMI). 2020 (Dic); 5(3): 114-116. doi: 10.32818/reccmi.a5n3a5.

Cite this as: Etxeberria-Lekuona D, Iridoy-Zulet AA. Lung adenocarcinoma with lepidic growth. Rev Esp Casos Clin Med Intern (RECCMI). 2020 (Dec); 5(3): 114-116. doi: 10.32818/reccmi.a5n3a5.

Autor para correspondencia: Daniel Etxeberria-Lekuona. daniel.etxeberria.lekuona@navarra.es

\section{Palabras clave \\ $\triangleright$ Adenocarcinoma \\ $\triangleright$ Cáncer de pulmón \\ $\triangleright$ Lepídico \\ $\triangleright$ Tirosina-quinasa}

\begin{abstract}
Resumen
El adenocarcinoma de pulmón es un tipo de cáncer caracterizado por la existencia de múltiples subtipos histológicos con una gran variedad de manifestaciones clínicas y radiológicas. Varios de ellos presentan un característico crecimiento lepídico sobre la superficie alveolar que no invade las estructuras subyacentes. Presentamos el caso de un paciente de 60 años con un debut clínico compatible con una neumonía multilobar. Después del ingreso hospitalario se llegó al diagnóstico de un adenocarcinoma pulmonar de patrón lepídico. El paciente recibió tratamiento oncológico con fármacos inhibidores de la tirosina-quinasa en base a la farmacogenética del tumor.
\end{abstract}

Abstract
Lung adenocarcinoma is a type of cancer characterized by the presence of multiple histological subtypes with a
wide variety of clinical and radiological manifestations. Some of them show a remarkable lepidic growth on the
alveolar surface without invading the underlying structures. We report a 60-year-old patient with a clinical onset
suitable with multilobar pneumonia. After hospitalization, the diagnostic tests concluded the presence of a lepidic
pattern lung adenocarcinoma. The patient received oncological treatment with tyrosine kinase inhibitor drugs
based on the tumor pharmacogenetics.

\section{Puntos destacados}

$\triangleright$ Los cuadros compatibles con neumonía requieren un control evolutivo para confirmar la resolución de la misma y descartar diagnósticos alternativos.

$\triangleright$ Las imágenes en vidrio deslustrado plantean un amplio diagnóstico diferencial.

\section{Introducción}

El adenocarcinoma (AC) de pulmón es el tipo histológico más frecuente de cáncer de pulmón $(C P)^{1}$. Se dice que un $A C$ tiene un crecimiento lepídico cuando se produce una proliferación de células neoplásicas que revisten las superficies de las paredes alveolares preservando la arquitectura pulmonar ${ }^{2}$. Se describe el caso de un paciente que debutó con un cuadro neumónico, al que, gracias al seguimiento tras el alta hospitalaria, se le diagnostico finalmente de enfermedad neoplásica.

\section{Caso clínico}

Antecedentes y enfermedad actual

Paciente varón de 60 años, fumador hasta los 40, sin antecedentes de interés. Trabajaba en un taller de frigoríficos de camiones de poliéster.

En sus antecedentes familiares destacaba que su padre había fallecido por CP. Se le valoró en la consulta de Medicina Interna (MI) cinco semanas tras el alta de un ingreso hospitalario en el que había presentado un cuadro febril secundario a neumonía de lóbulos inferiores con derrame pleural derecho. Había evolucionado favorablemente con el tratamiento antibiótico de ceftriaxona y levofloxacino.

\section{Exploración física}

Durante el ingreso se había intentado realizar una toracocentesis diagnóstica a ciegas sin obtener muestra de líquido pleural (Figura 1). En la consulta el 
paciente refería persistencia de escasa expectoración blanquecina y disnea al caminar rápido en llano o subir pequeñas pendientes. No presentaba fiebre u otra sintomatología.

En la exploración física presentaba una saturación de $\mathrm{O}_{2}$ basal del 94\%, siendo el resto de las constantes normales. En la auscultación pulmonar se apreciaban crepitantes secos en bases, con buena ventilación en el resto campos. El resto de la exploración era normal.

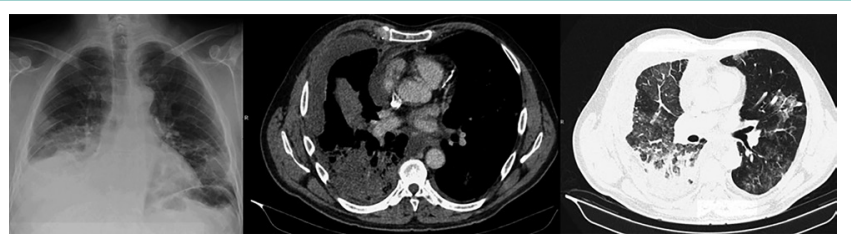

Figura 1. Imágenes de radiografía simple y TAC del ingreso inicial que muestran neumonía multilobar con predominio de lóbulo inferior derecho y derrame pleural derecho loculado. En la TAC se observan áreas de consolidación y de aumento de densidad en vidrio deslustrado multifocales con mayor afectación del pulmón derecho.

\section{Pruebas complementarias}

Cinco días antes de la consulta el paciente se había un realizado un estudio analítico en el que no se apreciaban alteraciones significativas, incluyendo un hemograma y una determinación de PCR normales. Aportaba estudios serológicos para Chlamydia pneumoniae, Chlamydia psittaci, Legionella pneumophila, Coxiella burneti y Mycoplasma pneumoniae realizados durante el ingreso y tras el alta, que fueron negativos.

En la consulta se solicitó una radiografía de tórax en la que se constató que persistían infiltrados en lóbulos inferiores con un aumento de densidad en el lóbulo superior derecho de nueva aparición (Figura 2).

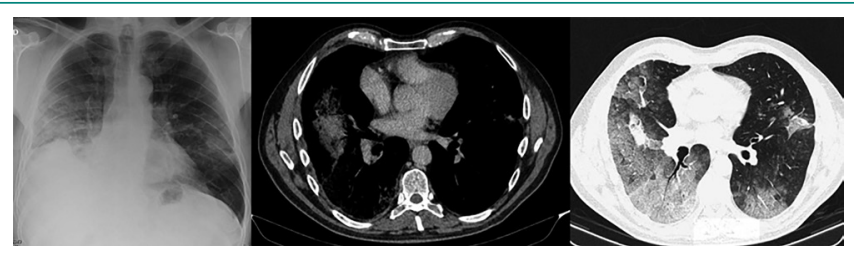

Figura 2. Control evolutivo después del ingreso inicial. La neumonía es más extensa que en el estudio previo, con disminución de las áreas de condensación, predominio de las imágenes en vidrio deslustrado y resolución del derrame pleural.

\section{Evolución}

Se solicitó una TAC de tórax que mostró una afectación parenquimatosa bilateral, generalizada, en vidrio deslustrado, que solo respetaba la mayor parte del lóbulo superior izquierdo y el vértice del lóbulo superior derecho. Se apreciaba además una pequeña área parcheada de condensación en lóbulo inferior derecho, sin derrame pleural (Figura 2). Estos hallazgos radiológicos planteaban un amplio cuadro de diagnóstico diferencial (Tabla 1).
- Neumonías intersticiales idiopáticas: NINE, NID, bronquiolitis respiratoria asociada a EPI, NIA, neumonía intersticial linfocítica, NOC

- Alveolitis alérgica extrínseca aguda

- Eosinofilia pulmonar

- Histiocitosis X

- Sarcoidosis

- Proteinosis alveolar

- Daño alveolar difuso / SDRA

- Edema pulmonar

- Hemorragia alveolar

- Infección: neumonía atípica, virus, Pneumocystis jiroveci

- Adenocarcinoma pulmonar

- Otras: Neumonía lipoidea exógena, enfermedades del colágeno, neumoconiosis, toxicidad por drogas, linfoma

NINE: neumonía intersticial no específica idiopática; NID: neumonía intersticial difusa; EPI: enfermedad pulmonar intersticial; NIA: neumonía intersticial aguda; NOC: neumonía organizada criptogénica;

SDRA: síndrome de distrés respiratorio agudo

Tabla 1. Diagnóstico diferencial de las imágenes en vidrio deslustrado de la TAC

Se completó el estudio con una determinación de inmunoglobulinas lgA, lgG, IgM y lgE, marcador tumoral CEA (carcinoembryonic antigen), estudio de autoinmunidad (ANA, anti-DNA, ENA, FR, anti-CCP, C3, C4, ANCA, ECA, crioglobulinas), precipitinas para aves y Aspergillus fumigatus, Quantiferon-TB y serología de VIH. Todos los resultados fueron normales excepto el CEA que fue de $38 \mathrm{ng} / \mathrm{mL}$ (0-5).

Además se realizó una espirometría que mostró un patrón no obstructivo (FVC: 3,29 [72\%]; FEV1: 2,88 [80\%]; FEV1/FVC: 0,87) con prueba broncodilatadora negativa, y seguidamente una broncoscopia en la que no se objetivaron lesiones en la vía aérea, hallándose únicamente abundantes secreciones acuosas espumosas bilaterales. Se recogieron muestras con lavado broncoalveolar (BAL). Los cultivos del mismo en medio para aerobios, tuberculosis y hongos resultaron negativos.

Se realizó tinción PAS que resultó negativa y el estudio de citología mostró proliferación epitelial papilar atípica, planteando la posibilidad diagnóstica de hiperplasia neumocitaria atípica versus AC invasivo.

Finalmente se realizó una criobiopsia con diagnóstico de AC pulmonar invasivo con predominio de patrón lepídico. Dada la afectación difusa bilateral se correspondía con un estadio 4.

En el estudio genético de la pieza de biopsia pulmonar se apreció la presencia de una mutación de sensibilidad (deleción) para inhibidores de la tirosinaquinasa (ITK) en el exón 19 del gen EGFR (Epidermal Growth Factor Receptor).

Inicialmente el paciente recibió un ciclo de carboplatino-pemetrexed, $y$, tras conocer la presencia de la mutación, se le pautó tratamiento con un ITK del EGFR, el afatinib, que inició en octubre del 2018. Con dicho fármaco se consiguió una respuesta clínica favorable pero una respuesta radiológica solo parcial.

En agosto del 2019 se detectó en una TAC de control una progresión pulmonar radiológica, por lo que en octubre de 2019 se realizó una broncoscopia con BAL, confirmándose la persistencia del AC y la presencia de la mutación de resistencia T790M en el exón 20 del gen EGFR. Teniendo en cuenta este resultado el paciente empezó en noviembre 2019 un tratamiento de segunda línea con osimertinib con buena respuesta clínica y radiológica hasta la actualidad. 


\section{Diagnóstico}

Adenocarcinoma pulmonar lepídico estadio 4

\section{Discusión y conclusión}

Al tratarse de un varón de más de 50 años, exfumador, con una neumonía multilobar, se remitió a consulta para seguimiento evolutivo. Ante la persistencia de sintomatología y siguiendo las recomendaciones de las guías clínicas, se amplió el estudio de imagen mediante TAC de tórax³. Tras su valoración y ante el empeoramiento de la imagen, se decidió ampliar el proceso diagnóstico. Lo llamativo de este caso fue, más que la persistencia de una imagen alterada, el empeoramiento de la misma.

El CP es la causa más frecuente de muerte por cáncer en el mundo en ambos $\operatorname{sexos}^{4}$ y el AC es el subtipo más frecuente. Su incidencia ha aumentado en las últimas décadas en relación con el aumento del CP en mujeres. Por otra parte se ha planteado la hipótesis de que el consumo de cigarrillos con filtro, bajos en nicotina y alquitrán, también sea un factor favorecedor ${ }^{1,5}$

Las manifestaciones clínicas son variadas y, al igual que en otros tipos de CP, la mayoría de los pacientes que presenta síntomas en el momento del diagnóstico la enfermedad se encuentra en un estadio avanzado ${ }^{6}$. Las manifestaciones clínicas iniciales más frecuentes son: el síndrome constitucional, la tos, el dolor la disnea y la hemoptisis. De forma ocasional se diagnostica a algunos pacientes tras un proceso infeccioso, como es el caso que nos ocupa.

Histológicamente el AC pulmonar se caracteriza porque los tumores son heterogéneos, pudiendo formar glándulas o estructuras papilares y producir mucina. En algunos casos el AC presenta un patrón de crecimiento denominado lepídico, en el que las células tumorales proliferan sobre la superficie de las paredes alveolares intactas sin invadir el estroma, los vasos sanguíneos o la pleura. Este patrón es predominante en tres subtipos de AC: el AC in situ, el AC mínimamente invasivo y el AC invasivo subtipo lepídico o AC lepídico.

Al igual que la histología, la expresión radiológica del AC de pulmón es variada. Podemos encontrar opacidades en vidrio deslustrado, zonas de consolidación y lesiones en las que se combinan ambas. Puede debutar como una lesión aislada o como lesiones en múltiples niveles. En la TAC de alta resolución el patrón de crecimiento lepídico suele corresponder a imágenes en vidrio deslustrado, mientras que las áreas de consolidación, generalmente, corresponden a un tumor histológicamente invasivo².

En el diagnóstico de confirmación citohistológica del CP se debe intentar obtener una muestra suficiente para realizar el análisis inmunohistoquímico y genético complementario. En el AC en estadio avanzando se evalúa la pre- sencia de mutaciones que indiquen susceptibilidad a tratamientos dirigidos específicamente contra dianas concretas de las células tumorales, entre las que se incluye el EGFR y la ALK (anaplastic lymphoma kinase)'. El tratamiento de un caso como el que exponemos, se basa en la quimioterapia. Si se constata la presencia de mutaciones de susceptibilidad en el EGFR la primera línea de tratamiento serán los ITK. Este es el esquema de tratamiento con el que se está tratando a nuestro paciente $e^{7,8}$.

Con el caso clínico que presentamos en este artículo queremos demostrar la importancia del seguimiento evolutivo de las imágenes radiológicas inespecíficas. Su empeoramiento, como en nuestro paciente, ha de hacernos replantear el diagnóstico etiológico inicial y considerar la realización de nuevas pruebas complementarias.

\section{Bibliografía}

1. Barta JA, Powell CA, Wisnivesky JP. Global Epidemiology of Lung Cancer Ann Glob Health. 2019; 85(1): 8, 1-16. doi: 10.5334/aogh.2419.

2. Travis WD, Brambilla E, Nicholson AG, Yatabe Y, Austin JHM, Beasley MB, et al.; WHO Panel. The 2015 World Health Organization Classification of Lung Tumors: Impact of Genetic, Clinical and Radiologic Advances Since the 2004 Classification. J Thorac Oncol. 2015; 10(9): 1243-1260. doi: 10.1097/ JTO.0000000000000630.

3. Lim WS, Baudouin SV, George RC, Hill AT, Jamieson C, Le Jeune I, et al.; Pneumonia Guidelines Committee of the BTS Standards of Care Committee. BTS guidelines for the management of community acquired pneumonia in adults: update 2009. Thorax. 2009; 64 Suppl 3: iii1-55. doi: 10.1136/ thx.2009.121434

4. Global Burden of Disease Cancer Collaboration, Fitzmaurice C, Dicker D, Pain A, Hamavid H, Moradi-Lakeh M, MacIntyre MF, et al. The Global Burden of Cancer 2013. JAMA Oncol. 2015; 1(4): 505-27. doi: 10.1001/jamaoncol.2015.0735.

5. Leiro-Fernández V, Mouronte-Roibás C, Ramos-Hernández C, Botana-Rial M, González-Piñeiro A, García-Rodríguez E, et al. Changes in clinical presentation and staging of lung cancer over two decades. Arch Bronconeumol. 2014; 50(10): 417-21. doi: 10.1016/j.arbres.2014.03.003.

6. Chute CG, Greenberg ER, Baron J, Korson R, Baker J, Yates J. Presenting conditions of 1539 population-based lung cancer patients by cell type and stage in New Hampshire and Vermont. Cancer. 1985; 56(8): 2107-11. doi: 10.1002/1097-0142(19851015)56:8<2107::aid-cncr2820560837>3.0.co;2-t.

7. Reck M, Rabe KF. Precision Diagnosis and Treatment for Advanced NonSmall-Cell Lung Cancer. N Engl J Med. 2017; 377(9): 849-861. doi: 10.1056/ NEJMra1703413.

8. Villar Álvarez F, Muguruza Trueba I, Belda Sanchis J, Molins López-Rodó L, Rodríguez Suárez PM, Sánchez de Cos Escuín J, et al. Executive summary of the SEPAR recommendations for the diagnosis and treatment of non-small cell lung cancer. Arch Bronconeumol. 2016; 52(7):378-88. doi: 10.1016/j. arbres.2016.02.016 